\title{
ANÁLISE DA PRODUTIVIDADE DE UM SISTEMA DE COLHEITA DE ÁRVORES INTEIRAS NO NORTE DO ESTADO DE GOIÁS
}

\author{
Nilton Cesar Fiedler ${ }^{1}$, Eduardo Braga da Rocha ${ }^{2}$, Eduardo da Silva Lopes ${ }^{3}$ \\ ${ }^{1}$ Eng. Florestal, Dr., Depto. de Engenharia Florestal, UFES, Alegre, ES, Brasil - fiedler@pq.cnpq.br \\ ${ }^{2}$ Eng. Florestal, M.Sc., Depto. de Engenharia Florestal, UnB, Brasília, DF, Brasil - edubraga@unb.br \\ ${ }^{3}$ Eng. Florestal, Dr., Depto. de Engenharia Florestal, UNICENTRO, Irati, PR, Brasil - eslopes@irati.unicentro.br \\ Recebido para publicação: 06/08/2007 - Aceito para publicação: 10/03/2008
}

\begin{abstract}
Resumo
Esta pesquisa teve por objetivo analisar a produtividade de um sistema de colheita florestal de árvores inteiras em povoamentos de Eucalyptus grandis, visando a melhoria do sistema e a otimização da produção. O estudo foi conduzido em uma empresa florestal no norte do estado de Goiás. O sistema de colheita florestal era constituído por um feller-buncher, um skidder, uma garra traçadora e um carregador florestal. A análise técnica das máquinas abordou um estudo de tempos e movimentos pelo método de tempo contínuo, em que as operações foram divididas em fases do ciclo de trabalho. Foram determinadas as disponibilidades mecânicas, a eficiência operacional e a produtividade efetiva. Os resultados indicaram que o carregador florestal, apesar de apresentar a melhor disponibilidade mecânica $(96,8 \%)$, teve a menor eficiência operacional (40,3\%). Já o feller-buncher teve a menor disponibilidade mecânica $(47,1 \%)$ devido ao elevado número de interrupções ocorridas durante o ciclo de trabalho. A garra traçadora teve a melhor produtividade do sistema ( $84 \mathrm{~m}^{3}$ por hora efetiva). A análise de regressão apontou que a produtividade do feller-buncher foi influenciada pela distância e pelo volume da madeira, o skidder foi influenciado pela distância e pelo volume do feixe de árvores e o traçador mecânico pelo volume da madeira.

Palavras-chave: Colheita de madeira; planejamento da colheita florestal; análise de produtividade.
\end{abstract}

\begin{abstract}
Analysis of productivity on complete tree harvesting system in north of the Goias State, Brazil . This research had as objective to analysis the productivity in full tree harvesting system in a stand of eucalyptus to improve and provide the production system optimization. The study was developed in a forest company located in the North Goias State. The harvesting wood system consisted on the use of feller-buncher, skidder, grapple saw and forest loader. The technical of analysis the machines consisted on movement and time study for the continuous method, where the operations in work cycle. The productivity, mechanical availability and operational efficiency were determined. The results indicated that the forest loadder was machine with the lesser operational efficiency $(40,3 \%)$. The lesser mechanical availability was the feller-buncher $(47.1 \%)$, dere to bigger interruption occurred in working cycle. The grapple saw had in the highest productivity $\left(84 \mathrm{~m}^{3} / \mathrm{hf}\right)$. The regression analysis indicated that the feller-buncher productivity was influenced by distance and wood volume, while the skidder by distance and tree buncher volume and the grapple saw by wood volume.

Keywords: Timber harvesting; timber forest planning; productivity analysis.
\end{abstract}

\section{INTRODUÇÃO}

O setor florestal brasileiro tem passado por mudanças significativas nas últimas décadas. O crescimento da economia, a estabilização da política monetária e a abertura do mercado nacional ao mundo globalizado têm possibilitado às empresas florestais a obtenção de melhor competitividade e, por conseguinte, a execução das atividades florestais com máquinas e equipamentos modernos e de elevada produtividade.

Apesar de muitas empresas florestais estarem utilizando modernas tecnologias em suas etapas de produção, elas precisam aperfeiçoar os sistemas de trabalho. Em se tratando de colheita florestal, as 
atividades são complexas e altamente onerosas, dependendo, economicamente, de um planejamento adequado de todo o processo produtivo.

Segundo Machado; Lopes (2000), as atividades de colheita e transporte florestal são de grande importância do ponto de vista econômico, devendo ser planejadas visando à redução dos custos, que chegam a representar mais de $50 \%$ dos custos totais da madeira posta no pátio da indústria. Dessa forma, a redução nos custos poderá promover a competitividade das indústrias florestais tanto no mercado interno como no externo (BRAMUCCI, 2001).

No Brasil, embora o número de estudos realizados nessa área sejam ainda reduzidos, muitas empresas estão alcançando resultados bastante expressivos na implantação de sistemas mecanizados de colheita florestal (BRAMUCCI, 2001). A utilização planejada de sistemas mecanizados de colheita florestal permite a organização, a racionalização e a otimização das atividades, contribuindo para a melhoria da qualidade do produto e do serviço, melhoria das condições de trabalho do ser humano, aumento de produtividade das operações e redução dos custos operacionais e de produção.

De acordo com Bramucci; Seixas (2002), o uso de sistemas mecanizados de colheita florestal é afetado por diversas variáveis que interferem na capacidade operacional dos equipamentos e, conseqüentemente, no custo final. No Brasil existem ainda poucos dados a respeito da real influência dessas variáveis e da produtividade das máquinas em determinadas condições de trabalho.

Nas análises das operações de processamento mecanizado (desgalhamento, traçamento, destopamento e pré-extração) em florestas de eucalipto utilizando processador com rodados de pneus, Santos; Machado (1995) observaram que a capacidade produtiva das máquinas crescia com o aumento do volume por árvore até atingir um máximo, com um volume por árvore de $0,34 \mathrm{~m}^{3}$, decrescendo a partir desse valor. No caso de sistemas de colheita de árvores inteiras, o volume de madeira por hectare foi a principal variável de influência na operação de corte com o feller-buncher, apresentando melhor desempenho em talhões com espaçamentos maiores (BRAMUCCI; SEIXAS, 2002). Os mesmos autores afirmam ainda que a produtividade do skidder foi melhor estimada por meio de equação que incluiu as variáveis volume por hectare e distância de arraste.

Portanto, para diminuir os custos de produção em sistemas mecanizados, torna-se necessária a realização de pesquisas para se conhecerem as reais capacidades produtivas e as possíveis variáveis que interferem no rendimento das máquinas de colheita florestal, com vistas ao desenvolvimento de técnicas que melhorem o desempenho operacional do sistema de colheita, maximizando a produtividade e reduzindo os custos (SILVA et al., 2003).

O objetivo desta pesquisa foi realizar uma análise da produtividade de um sistema de colheita florestal de árvores inteiras em povoamentos de Eucalyptus grandis, visando à otimização do sistema de produção.

\section{MATERIAL E MÉTODOS}

\section{Área de estudo}

A pesquisa foi desenvolvida em áreas de colheita de madeira de uma empresa florestal localizada no norte de Goiás. A região está localizada entre as coordenadas geográficas $14^{\circ} 20^{\prime} 34^{\prime \prime}$ de latitude Sul e $48^{\circ} 20^{\prime} 06^{\prime \prime}$ de longitude Oeste. O clima é caracterizado como quente (tropical semi-úmido), com período chuvoso entre outubro e abril, e período seco entre maio e setembro. Temperatura média é de $27^{\circ} \mathrm{C}$ no período chuvoso e $25{ }^{\circ} \mathrm{C}$ no período seco, enquanto a umidade relativa do ar média é de $77 \%$ e $51 \%$ nos períodos chuvoso e seco, respectivamente (SOUZA, 2003).

$\mathrm{O}$ povoamento florestal utilizado na pesquisa possuía uma área plana de 50 hectares e era composto de Eucalyptus grandis, com oito anos de idade, altura comercial média de $18 \mathrm{~m}$, DAP médio de $15,4 \mathrm{~cm}$, volume médio por árvore de $0,165 \mathrm{~m}^{3}$ e média de 1.549 indivíduos por hectare (máximo de 1660 e mínimo de 1500 árvores por hectare), com um volume médio de $256 \mathrm{~m}^{3} /$ ha. O solo é de textura areno/argilosa, drenado, com relevo plano.

\section{Descrição do sistema de colheita florestal}

O sistema de colheita florestal era caracterizado por um módulo composto de quatro máquinas: trator florestal derrubador-empilhador (feller-buncher), trator florestal arrastador (skidder), traçador mecânico (garra traçadora) e carregador florestal. Nesse módulo, ofeller-buncher realizava as operações de derrubada das árvores e o amontoamento em feixes, trabalhando em eitos de quatro linhas. $\mathrm{O}$ arraste 
dos feixes de árvores até a beira da estrada era realizado por um skidder. Em seguida, a garra traçadora realizava o processamento das árvores em toras de comprimento de $5,70 \mathrm{~m}$, seguido pelo empilhamento. Por fim, o carregamento da madeira sobre os veículos de transporte principal era realizado por um carregador florestal.

\section{Caracterização das máquinas avaliadas}

O feller-buncher era composto por uma escavadeira de acionamento hidráulico de esteiras, marca Caterpillar, modelo CAT 320C L, motor Mitsubishi de potência nominal de 138 HP. O cabeçote da máquina era composto por sistema de disco, marca Rotosaw CHO 1214, modelo MS-2001, com potência de rotação entre 2.280 a $2.320 \mathrm{rpm}$ e braços acumuladores. A capacidade de corte era de até $55 \mathrm{~cm}$ de diâmetro e alcance máximo de 7,6 m, acumulando em média até 6 árvores por ciclo.

O skidder avaliado era composto por um trator florestal com rodados de pneus, marca Caterpillar, modelo 525B, tração 4X4 e potência nominal de $180 \mathrm{HP}$.

A garra traçadora era composta por uma máquina-base com rodados de esteiras, marca Caterpillar, modelo CAT 320C L, com potência nominal de 138 HP. A máquina estava equipada com uma garra traçadora da marca Hultdins, modelo 400S Super Griffer, com motor hidráulico de 37 HP de potência nominal, área de $37 \mathrm{~cm}^{2}$ e alcance médio de $7,6 \mathrm{~m}$.

O carregador florestal era composto por uma escavadeira de acionamento hidráulico de esteiras, marca Caterpillar, modelo CAT 320C L, com potência nominal de $138 \mathrm{HP}$, equipado com garra da marca Hultdins, modelo 400S Super Griffer, de área de $37 \mathrm{~cm}^{2}$ e alcance médio de 7,6 $\mathrm{m}$.

\section{Descrição das atividades do ciclo de trabalho}

O feller-buncher se direciona para o talhão a ser cortado em eitos de quatro linhas. A máquina se posiciona no sentido oposto à posição de tombamento, realizando um giro da lança de uma média de $180^{\circ}$ para o tombamento dos três primeiros feixes abatidos. Esse movimento favorece a colocação das árvores em posição apropriada para a realização do arraste. Após a realização dos três primeiros ciclos, o fellerbuncher passa a derrubar as quatro linhas de corte em sentido favorável à linha de tombamento, girando a máquina em um ângulo médio de 30 a $45^{\circ}$ graus.

$\mathrm{Na}$ fase de arraste, o skidder se desloca da pilha de madeira localizada na margem do talhão até os feixes de árvores no seu interior. O trator apanha os feixes próximos à margem do talhão em marcha ré. Em todas as situações, a máquina se posiciona de traseira na direção do feixe a ser arrastado, aciona a garra, o apanha e suspende parcialmente a carga, arrastando-a até o próximo feixe posicionado na mesma linha de tombamento. Novamente, com o acionamento da garra, libera a primeira carga em cima do segundo feixe e os agarra e suspende novamente. Dependendo do número de árvores, agarra-se até três feixes de árvores, arrastando-os até a margem da estrada, onde são depositados sobre a pilha de madeira. Depois da formação das pilhas, ocorre o acerto da pilha com o auxílio da lâmina frontal, para que a base das árvores fique retilínea.

A garra traçadora direciona sua lança para a pilha de madeira, apanha o feixe de árvores com o acionamento da garra hidráulica, puxa-o para a margem do talhão e o libera. Novamente a lança é deslocada com auxílio de um gabarito a seis metros da base do feixe. Aciona-se a garra, apanhando o feixe e suspendendo-o. Nessa etapa, ativa-se o sabre da motosserra, realizando o traçamento das árvores. Após a realização do corte, a lança puxa outra vez o feixe para o início da pilha de toras e o libera. Desse modo se repetem os movimentos com o mesmo feixe de madeira até o completo traçamento das árvores.

$\mathrm{Na}$ operação de carregamento, o carregador florestal é posicionado no início da pilha de madeira, desloca sua lança em direção à pilha, acionando a garra e prendendo o feixe de toras. Com o auxílio do motorista do veículo, o operador movimenta o braço hidráulico do carregador até o compartimento de carga do veículo de transporte, acionando a grua e liberando as toras.

\section{Coleta dos dados}

Os dados foram coletados no período de janeiro a agosto de 2005. A jornada diária de trabalho das operações de derrubada, arraste e traçamento era de 22 horas, enquanto o carregamento era de 11 horas (turno diurno). Cada máquina era operada por quatro operadores em sistema de revezamento, trabalhando em dias alternados, enquanto o carregador florestal possuía dois operadores, trabalhando em sistema de revezamento a cada três dias trabalhados. 
Inicialmente, foi realizado um estudo de tempos e movimentos-piloto de cada máquina, buscando-se definir o número de observações necessárias para proporcionar um erro de amostragem máximo de 5\%, conforme a seguinte expressão (BARNES, 1977):

$$
\mathrm{n} \geq \frac{\mathrm{t}^{2} \times C V^{2}}{\mathrm{E}^{2}}
$$

Em que: $\mathrm{n}=$ número mínimo de ciclos necessários; $\mathrm{t}=$ valor de $\mathrm{t}$ para o nível de probabilidade desejado $\mathrm{e}$ $(n-1)$ graus de liberdade; $\mathrm{CV}$ = coeficiente de variação, em porcentagem; $\mathrm{E}=$ erro admissível, em porcentagem.

Após definidos os ciclos mínimos necessários para cada máquina, procedeu-se ao estudo de tempos e movimentos em todos os turnos de trabalho.

\section{Análise técnica}

A análise técnica das máquinas baseou-se na realização de um estudo de tempos e movimentos, determinando-se a disponibilidade mecânica, a eficiência operacional e a produtividade efetiva.

\section{Estudo de tempos e movimentos}

Foi utilizado o método de tempo contínuo, com a medição dos tempos sem detenção do cronômetro. Utilizou-se um cronômetro centesimal da marca Vitesse e formulários específicos, conforme o ciclo operacional de cada máquina.

\section{Disponibilidade mecânica}

A disponibilidade mecânica foi obtida por meio da relação entre o tempo de trabalho total destinado para a realização das atividades, em que a máquina encontrava-se apta para o desempenho de suas funções, e o período em que a mesma interrompia o trabalho por encontrar-se em manutenção. Foi utilizada a seguinte expressão (BIRRO et al., 2004):

$$
\mathrm{DM}=\frac{H T-H M}{H T} \times 100
$$

Em que: DM = disponibilidade mecânica; HT = horas totais de trabalho; HM = horas em manutenção.

\section{Eficiência operacional}

A eficiência operacional foi considerada como a relação existente entre o tempo de trabalho efetivo do dia de trabalho, em que a máquina encontrava-se em atividade, e o período em que a máquina interrompia o trabalho por qualquer motivo. Foi utilizada a seguinte expressão apresentada por Birro (2002):

$$
\mathrm{EOp}=\frac{T e f}{T e f+H i} \times 100
$$

Em que: EOp = eficiência operacional; Tef $=$ tempo de trabalho efetivo, em horas; $\mathrm{Hi}=$ horas de interrupções operacionais.

\section{Produtividade efetiva}

A produtividade foi determinada em metros cúbicos por hora efetiva de trabalho, utilizando-se a seguinte expressão, conforme modelo sugerido por Minette (2004):

$$
\operatorname{Pef}\left(\mathrm{m}^{3} / \mathrm{hf}\right)=\frac{\sum V o l \times 360000}{\sum T e f}
$$

Em que: Pef = produtividade efetiva; $\mathrm{Vol}=$ volume produzido; $T e f=$ tempo efetivo de trabalho. 


\section{Análise estatística}

As análises estatísticas foram realizadas por meio de análise de regressão, utilizando-se o programa SPSS 11.0, de modo a se verificar a relação entre as variáveis dependentes (tempo total do ciclo operacional e produtividade) e as variáveis independentes (distância percorrida, número de árvores por ciclo, tempo de experiência do operador e fatores ambientais). Para a análise estatística das equações, utilizaram-se como critérios de seleção as equações de tempo total do ciclo operacional e de produtividade com maior coeficiente de determinação $\left(\mathrm{R}^{2}\right)$, seguidas pelo menor número de variáveis independentes associadas.

Para relacionar a dependência, foi estabelecido o método de regressão Stepwise, ao nível de 5\% de significância. As variáveis testadas que não apresentaram influência estatística significante foram dispensadas do modelo.

\section{RESULTADOS E DISCUSSÃO}

\section{Análise técnica}

Feller-buncher

Neste estudo, realizou-se a coleta de 1.240 ciclos operacionais, enquanto o estudo-piloto mostrou a necessidade da coleta de 129 ciclos. O tempo total utilizado para a execução do trabalho foi de 37,7 horas, tendo sido derrubadas 3.858 árvores.

A constituição média dos elementos do ciclo operacional do feller-buncher é mostrada na figura 1. Como pode ser visto, os elementos que consumiram a maior parte do tempo do ciclo operacional foram a derrubada das árvores e o deslocamento da máquina, com $17 \%$ e $13,5 \%$ do tempo total.

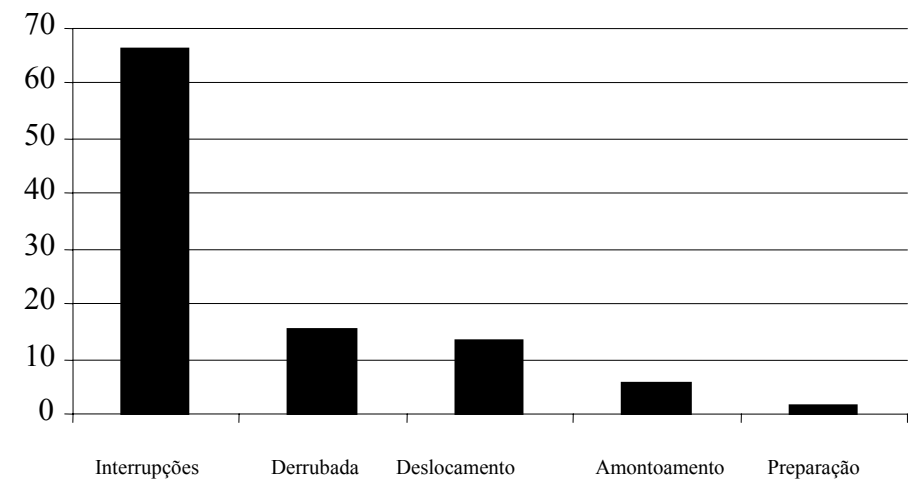

Figura 1. Composição percentual do ciclo operacional do feller-buncher.

Figure 1. Percent composition of the operational cycle of the feller-buncher.

O elevado percentual de tempo de interrupções acarretou uma eficiência operacional de apenas $35,6 \%$. As maiores interrupções ocorreram no turno diurno, devido às manutenções mecânicas programadas para esse período, em função da complexidade e das condições favoráveis de iluminação para a realização dos serviços. No período noturno, a eficiência operacional média foi de 56,5\%, sendo que a principal interrupção observada foi causada pela troca de bits do disco de corte do cabeçote.

A disponibilidade mecânica média foi de 47,1\%, mas pelo histórico da empresa ao longo dos três primeiros meses de 2005 , a mesma era de $78,0 \%$. Tal diferença é explicada pela coleta dos dados ter sido realizada próximo ao período programado para a manutenção preventiva, em que a máquina apresentou maior probabilidade de apresentar falhas mecânicas.

Durante a coleta dos dados, foram derrubadas, em média, 3,1 árvores por ciclo de trabalho, sendo a produtividade por hora efetiva de trabalho média de $47,3 \mathrm{~m}^{3}$. A duração média do ciclo de trabalho foi de 109,56 segundos. 
Para análise do skidder, o estudo de tempos e movimentos inicial mostrou a necessidade de uma observação mínima de 184 ciclos operacionais, tendo sido cronometrados 463 ciclos, de forma a garantir maior confiabilidade na análise.

A tabela 1 mostra os tempos de trabalho do ciclo operacional do skidder. Como pode ser verificado, os elementos parciais que consumiram o maior tempo do ciclo operacional foram o arraste, a viagem com carga e as manobras, com 22,7,21,7 e 16,3\% do tempo total, respectivamente.

Tabela 1. Distribuição dos tempos de trabalho do skidder para uma distância média de arraste de 230 metros.

Table 1. Distribution of the times of work in the skidder to medium distance of draw of 230 meters.

\begin{tabular}{lccc}
\hline Elementos do ciclo operacional & $\begin{array}{c}\text { Tempo médio } \\
\text { (s) }\end{array}$ & $\begin{array}{c}\text { Tempo médio } \\
\text { (\%) }\end{array}$ & $\begin{array}{c}\text { Tempo total } \\
\text { (h) }\end{array}$ \\
\hline Tempo de viagem sem carga & 58,1 & 21,7 & 7,5 \\
Tempo de manobras & 43,7 & 16,3 & 5,6 \\
Tempo de carregamento & 26,4 & 9,9 & 3,4 \\
Tempo de arraste & 60,6 & 22,7 & 7,8 \\
Tempo de descarregamento & 7,0 & 2,6 & 0,9 \\
Tempo de interrupções & 71,7 & 26,8 & 9,2 \\
Tempo total do ciclo & 267,5 & 100,0 & 34,4 \\
\hline
\end{tabular}

As interrupções contribuíram com $26,8 \%$ do tempo total, enquanto a disponibilidade mecânica foi de $90,9 \%$, acarretando uma eficiência operacional média de $73,2 \%$. Conforme histórico da empresa ao longo dos três primeiros meses de 2005 , a disponibilidade mecânica foi de $90,0 \%$, retratando com fidelidade as tendências apresentadas pela máquina.

O tempo médio do ciclo operacional do skidder no arraste foi de 267,5 segundos. Apesar de a iluminação ter contribuído positivamente para a execução da atividade no período diurno, as manutenções, que são realizadas apenas no período diurno, influenciaram significativamente para a queda na eficiência operacional da máquina.

O tempo total de observação do skidder foi de 34,4 horas, sendo que o número médio de árvores arrastadas foi de 13,9 árvores por ciclo. A produtividade média por hora efetiva de trabalho foi de $42,3 \mathrm{~m}^{3}$ para uma distância média de arraste de 230 metros.

\section{Garra traçadora}

Neste estudo, foram coletados dados de 674 ciclos operacionais, enquanto o estudo-piloto mostrou a necessidade de coleta de 185 ciclos.

A tabela 2 mostra a distribuição dos tempos de trabalho da garra traçadora. Como pode ser visto, os elementos parciais que consumiram o maior tempo foram os tempos de pegada, soltura e traçamento, com $19,3,15,0$ e $14,0 \%$ do tempo total, respectivamente. O tempo de deslocamento demandou o menor tempo (1,6\%), pelo fato de o equipamento não apresentar movimentação constante e trabalhar na maior parte do tempo estacionado.

Tabela 2. Distribuição dos tempos da garra traçadora para uma média de 6,9 árvores traçadas por ciclo.

Table 2. Distribution of the times of work of the grapple saw to average of 6,9 tree shaw by cicle.

\begin{tabular}{lccc}
\hline $\begin{array}{l}\text { Elementos do ciclo } \\
\text { operacional }\end{array}$ & $\begin{array}{c}\text { Tempo médio } \\
\text { (s) }\end{array}$ & $\begin{array}{c}\text { Tempo total } \\
\text { (\%) }\end{array}$ & $\begin{array}{c}\text { Tempo total } \\
\text { (h) }\end{array}$ \\
\hline Tempo de deslocamento & 9,9 & 11,1 & 0,24 \\
Tempo de pegadas & 15,7 & 17,5 & 2,93 \\
Tempo de puxadas & 8,6 & 9,6 & 1,61 \\
Tempo de traçamento & 11,3 & 12,6 & 2,12 \\
Tempo de soltura & 12,0 & 13,4 & 2,26 \\
Tempo de interrupções & 32,1 & 35,8 & 6,00 \\
Tempo total & 89,6 & 100,0 & 15,16 \\
\hline
\end{tabular}


O maior tempo do ciclo operacional consumido deveu-se às interrupções, correspondendo a $35,8 \%$ do tempo total, ocasionadas, em mais de $70 \%$ dos casos, pelas trocas de correntes do sabre para afiação.

O número médio de árvores traçadas por feixe foi de 6,9 por ciclo. A produtividade média por hora efetiva foi de $84 \mathrm{~m}^{3}$, com eficiência operacional média de 60,5\%. A disponibilidade mecânica foi de $75,2 \%$, sendo que, ao longo dos três primeiros meses de 2005, a disponibilidade mecânica foi de $83,0 \%$.

\section{Carregador florestal}

Em relação ao carregador florestal, o estudo-piloto determinou a coleta mínima de 372 ciclos operacionais, sendo que foram coletados 1.170 ciclos.

Como apresentado na tabela 3, o tempo médio do ciclo operacional foi de 129 segundos, proporcionando uma produtividade média por hora efetiva de $94,7 \mathrm{~m}^{3}$. O número médio de toras carregadas por ciclo foi de 15 unidades, com variação de uma a 35 unidades.

Como pode ser visto, os elementos movimento do braço vazio, carga e depósito consumiram o maior tempo do ciclo operacional, com 25,8, 25,7 e 25,0\% do tempo total, respectivamente, enquanto o ajuste das toras na grua para a realização do carregamento foi inexpressivo, com apenas $0,57 \%$ do tempo total.

Tabela 3. Distribuição dos tempos de trabalho do carregador florestal.

Table 3. Distribution of the times of work of the forest loader.

\begin{tabular}{lccc}
\hline Elementos do ciclo operacional & $\begin{array}{c}\text { Tempo médio } \\
\text { (s) }\end{array}$ & $\begin{array}{c}\text { Tempo médio (\%) } \\
\text { Tempo total } \\
\text { (h) }\end{array}$ & $\begin{array}{c}1,62 \\
\text { Tempo de deslocamento }\end{array}$ \\
Tempo de movimento do braço vazio & 7,9 & 3,3 & 2,36 \\
Tempo de carga & 4,3 & 5,2 & 1,25 \\
Tempo de ajuste das toras na grua & 24,6 & 2,8 & 0,16 \\
Tempo de depósito & 15,7 & 16,3 & 4,59 \\
Tempo de manobras & 16,2 & 10,4 & 6,94 \\
Tempo de interrupções & 77,5 & 10,7 & 25,11 \\
Tempo total do ciclo & 151,0 & 51,3 & 42,03 \\
\hline
\end{tabular}

O deslocamento da máquina correspondeu a 3,3\% do tempo total, enquanto que o tempo de carga correspondeu 2,8\%. O ajuste da carga representou $16,3 \%$ do tempo total, o que se explica pela baixa qualidade das pilhas de madeira processadas pela garra traçadora. A intervenção para melhoria da qualidade da pilha influenciará positivamente no ciclo de trabalho do carregador florestal.

O elemento depósito do feixe de madeira no compartimento de carga do veículo de transporte consumiu $10,4 \%$ do tempo total, o que se explica pela necessidade de atenção do operador na realização da carga conforme os padrões estabelecidos.

As interrupções consumiram $51,3 \%$ do tempo total, o que se explica pelo elevado tempo de espera pelos veículos de transporte. A disponibilidade mecânica foi de $96,8 \%$ e a eficiência operacional de $40,3 \%$, o que pode ser explicado pelo elevado tempo de espera do carregador florestal pelos veículos de transporte. Essa situação deve ser alterada para a otimização do sistema de trabalho e a redução dos custos finais de colheita.

\section{Análise de regressão das variáveis ciclo operacional e produtividade Feller-buncher}

As análises de regressão pelo método Stepwise das variáveis dependentes (ciclo operacional e produtividade) são mostrados na tabela 4. Para a variável dependente tempo do ciclo operacional, as variáveis distância de deslocamento total e volume de madeira explicaram juntas $92,0 \%$ do tempo total. O volume da madeira exerceu maior influência no tempo do ciclo operacional. A variável período de trabalho não influenciou a duração do ciclo operacional, sendo, portanto, descartada da equação de regressão.

Para a variável dependente produtividade, as variáveis distâncias de deslocamento total e volume da árvore acarretaram um coeficiente de correlação que explicou 53,0\% da produtividade do fellerbuncher. 
Tabela 4. Equações do ciclo operacional e de produtividade do feller-buncher.

Table 4. Operational cycle and productivity equation of the feller-buncher.

\begin{tabular}{lccc}
\hline Variáveis & Equação estimada & F & $\mathbf{R}^{2}$ \\
\hline Tempo do ciclo operacional & $\mathrm{Y}=6,242+1,039 \mathrm{DT}+38,359 \mathrm{Vol}$ & $3602^{*}$ & 0,92 \\
Produtividade & $\mathrm{Y}=34,538-(0,220 \mathrm{DT})+35,742 \mathrm{Vol}$ & $220^{*}$ & 0,53 \\
\hline DT: Distância de deslocamento total Vol: Volume * Significativo $5 \%$ 5\%
\end{tabular}

DT: Distância de deslocamento total; Vol: Volume; * Significativo a 5\%.

\section{Skidder}

As análises de regressão pelo método Stepwise para as variáveis dependentes ciclo operacional e produtividade são mostradas na tabela 5. Para o tempo do ciclo operacional, as variáveis distância de deslocamento e número de cargas explicaram $87,0 \%$ do tempo total. $\mathrm{O}$ volume do feixe não exerceu influência no tempo do ciclo operacional.

Tabela 5. Equações do ciclo operacional e de produtividade do skidder.

Table 5. Operational cycle and productivity equation of the skidder.

\begin{tabular}{lccc}
\hline Variáveis & Equação estimada & F & $\mathbf{R}^{\mathbf{2}}$ \\
\hline Tempo do ciclo operacional & $\mathrm{Y}=-19,659+0,566 \mathrm{DT}+31,806 \mathrm{NC}$ & $1011^{*}$ & 0,87 \\
Produtividade & $\mathrm{Y}=69,640-(0,231 \mathrm{DT})+21,186 \mathrm{Vol}$ & $219^{*}$ & 0,58 \\
\hline
\end{tabular}

DT: Distância de deslocamento total; NC: $\mathrm{n}^{\circ}$ de cargas; Vol: Volume; * Significativo a 5\%.

Pelas análises realizadas, verificou-se ainda que o turno de trabalho não influenciou no tempo do ciclo operacional e na produtividade, sendo a variável descartada da equação de regressão. A variável volume da madeira arrastada também não influenciou no tempo do ciclo operacional, pelo fato de o skidder avaliado apresentar elevada força de tração (180 HP), não comprometendo seu desempenho. Conforme explicado, a distância de arraste influenciou diretamente no aumento do tempo do ciclo operacional e na queda na produtividade do skidder.

Para a variável dependente produtividade, a distância de deslocamento total e volume da madeira apresentaram um coeficiente de correlação que explicou $58 \%$ da produtividade do skidder.

Garra traçadora

Na tabela 6 estão representadas as equações de regressão pelo método Stepwise para as variáveis dependentes tempo total do ciclo operacional e produtividade. Os elementos treinamento do operador, período de trabalho e volume da madeira explicaram juntos apenas $35 \%$ do tempo do ciclo operacional. $\mathrm{O}$ período diurno e o treinamento do operador influenciaram negativamente no acréscimo do ciclo de trabalho.

Tabela 6. Equações do ciclo operacional e de produtividade da garra traçadora.

Table 6. Operational cycle and productivity equation of the grapple saw.

\begin{tabular}{lccc}
\hline Variáveis & Equação estimada & F & $\mathbf{R}^{\mathbf{2}}$ \\
\hline Tempo do ciclo operacional & $\mathrm{Y}=56,794-(8,080 \mathrm{~T})-(20,109 \mathrm{PD})+10,448 \mathrm{Vol}$ & $89^{*}$ & 0,35 \\
Produtividade & $\mathrm{Y}=7,753+21,568 \mathrm{~T}+27,116 \mathrm{PD}+46,089 \mathrm{Vol}$ & $797^{*}$ & 0,81 \\
\hline
\end{tabular}

PD: período diurno; Vol: Volume; T: Treinamento; E: Experiência; * Significativo a 5\%.

A variável volume da madeira afetou, principalmente, a fase de traçamento, pois o excesso de árvores presentes na garra ocasionava com freqüência o travamento da corrente, obrigando o operador a movimentar o sabre da motosserra para o seu desprendimento, ou, quando necessário, balançar a garra para ocorrer a liberação do sabre.

Como pode ser observado, as variáveis treinamento, período de trabalho e volume explicaram $81 \%$ da produtividade da garra traçadora.

Carregador florestal

As análises de regressão pelo método Stepwise para as variáveis dependentes ciclo operacional e produtividade do carregador florestal são apresentados na tabela 7. 
Tabela 7. Equações do ciclo operacional e de produtividade do carregador florestal.

Table 7. Operational cycle and productivity equation of the forest loader.

\begin{tabular}{lccc}
\hline Variáveis & Equação estimada & F & $\mathbf{R}^{\mathbf{2}}$ \\
\hline Tempo do ciclo operacional & $\mathrm{Y}=29,131+1,512 \mathrm{DT}+30,315 \mathrm{NM}$ & $43^{*}$ & 0,38 \\
Produtividade & $\mathrm{Y}=81,236-(92,361 \mathrm{NM})+106,268 \mathrm{Vol}$ & $344 *$ & 0,56 \\
\hline DT: Distância de deslocamento total; NM: $\mathrm{n}^{\circ}$ de manobras; Vol: Volume; * Significativo a 5\%. & &
\end{tabular}

Como pode ser visto, as variáveis distâncias de deslocamento e número de manobras para correção da carga explicaram $38 \%$ do tempo do ciclo operacional. O volume da madeira processada não apresentou influência na equação de tempo do ciclo operacional, pois o carregamento era realizado com grua carregada com até 35 toras, sendo que, no decorrer da atividade, o carregamento era realizado de forma mais lenta, com número reduzido de toras.

As principais variáveis que influenciaram a produtividade do carregador florestal foram o número de manobras e volume de madeira carregada, que explicaram $56 \%$ da variação da produtividade. $\mathrm{O}$ número de manobras exerceu influência decrescente na produtividade, ocasionando maior tempo consumido no ciclo operacional e diminuição da produtividade. Isso demonstra a necessidade de um balanceamento da linha de produção.

\section{CONCLUSÕES}

Com base nos resultados obtidos, as principais conclusões desta pesquisa foram:

- A baixa eficiência operacional encontrada no feller-buncher $(56,5 \%)$ foi causada principalmente pela baixa disponibilidade mecânica da máquina (47,1\%).

- O elevado percentual de interrupções ocasionou uma baixa eficiência operacional do sistema de produção analisado. O skidder apresentou a maior eficiência operacional e ofeller-buncher a menor.

- O carregador florestal foi a máquina com a maior disponibilidade mecânica, no entanto a baixa eficiência operacional acarretada pelas interrupções para espera de veículos para carregamento comprometeu a sua produtividade média final.

- Os principais fatores que influenciaram no tempo do ciclo operacional e na produtividade do fellerbuncher foram a distância de deslocamento e o volume de madeira das árvores.

- A análise de regressão apontou que o ciclo operacional do skidder foi influenciado pela distância total percorrida e pelo número de feixes arrastados.

- O principal fator que influenciou o ciclo operacional e a produtividade da garra traçadora foi o volume da madeira processada.

\section{REFERÊNCIAS}

BARNES, R. M. Estudos de movimentos e de tempos - projeto e medida do trabalho. Tradução da 6. ed. Americana. São Paulo: E. Blucher, 1977. 635 p.

BIRRO, M. H.; MACHADO, C. C.; SOUZA, A. P.; MINETTI, L. J. Avaliação técnica e econômica da extração de madeira de eucalipto com "track-skidder" em região montanhosa. Revista Árvore: Viçosa, MG, v. 28, n. 2, p. 207-217, 2004.

BRAMUCCI, M. Determinação e qualificação de fatores de influencia sobre a produtividade de "Harvesters" na colheita de madeira. 50 f. Dissertação (Mestrado em Recursos Florestais) - Escola Superior de Agricultura Luiz de Queiroz, Piracicaba, 2001.

BRAMUCCI, M.; SEIXAS, F. Determinação e quantificação de fatores de influência sobre a produtividade de "harvesters" na colheita florestal. Scientia Forestalis, Piracicaba, n. 62, p. 62-74, 2002.

MACHADO, C. C.; LOPES, E. S. Análise da influência do comprimento de toras de eucalipto na produtividade e custo da colheita e transporte florestal. Revista CERNE Lavras, v. 6, n. 2, p. 124-129, 2000. 
MENDONÇA FILHO, W. F. Análise operacional de colheitadeiras florestais. Floresta e Ambiente, Rio de Janeiro, v.,7, n. 1, p. 265-278, 2000.

MinetTe, L. J.; MOREIRA, F. M. T.; SOUZA, A. P.; MACHADO. C. C.; SilVA, K. R. Análise técnica e econômica do forwarder em três subsistemas de colheita de florestas de eucalipto. Revista Árvore, Viçosa, MG, v. 28, n. 1, p. 91-97, 2004.

MOREIRA, F. M. T.; SOUZA, A. P.; MACHADO, C. C.; MINETTE, L. J.; KATIA, R. S. Avaliação operacional e econômica do "feller-buncher" em dois subsistemas de colheita de florestas de eucalipto. Árvore: Viçosa, MG, v. 28, n. 2. p. 199-205, 2004,.

SANTOS, S. L. M.; MACHADO, C. C. Análise técnica-econômica do processamento de madeira de eucalipto em áreas planas, utilizando o processador. Árvore. Viçosa, MG, v. 19, n. 3, p. 346-357, 1995.

SILVA. C. B.; SANT'ANNA, C. M.; MINETTE, L. J. Avaliação ergonômica do "feller-buncher" utilizado na colheita de eucalipto. Cerne. Lavras, v. 9, n. 1, p. 109-118, 2003.

SOUZA, D. R. História da CODEMIN. Goiânia: Terra, 2003. 300 p. 